\title{
Advanced Age Impairs Cardioprotective Function of Mesenchymal Stem Cell Transplantation from Patients to Myocardially Infarcted Rats
}

\author{
Yu Liu ${ }^{a, b}$ Tao Liu ${ }^{a}$ Jinsong Han ${ }^{a, b}$ Zhonglu Yang ${ }^{a}$ Xiaodong Xue $^{a}$ \\ Hui Jiang ${ }^{\text {a Huishan Wang }}{ }^{\text {a }}$ \\ ${ }^{a}$ Department of Cardiovascular Surgery, Shenyang Northern Hospital, Shenyang, and ${ }^{\mathrm{b}}$ Department of \\ Cardiovascular Surgery, Xijing Hospital, Fourth Military Medical University, Xian, PR China
}

\section{Key Words}

Mesenchymal stem cells · Coronary artery disease .

Advanced age $\cdot$ Myocardial infarction

\section{Abstract}

Objectives: Mesenchymal stem cells (MSCs) have limited clinical therapeutic effects in older myocardial infarction (MI) patients. Thus, whether younger MSCs might confer greater protection is worth investigating. Methods: Human MSCs (hMSCs) were isolated before coronary artery bypass graft surgery and growth characteristics of hMSCs at passage 3 were observed. Vascular endothelial growth factor (VEGF) and $\mathrm{Bcl}-2$ mRNA and protein expression from hMSCs were measured. In vivo, 45 adult male rats with $\mathrm{MI}$ were randomized to receive one of three treatments: old hMSCs, young hMSCs or culture medium (control) transplanted into infarcted myocardium. Echocardiography, TUNEL, immunohistochemistry and Western blot were used to assess results. Results: hMSC proliferation in the old group was significantly lower than the young group. VEGF decreased $35 \%$ and $\mathrm{BCl}-2$ decreased more than $60 \%$ at the mRNA level; VEGF and Bcl-2 protein were decreased in the old versus the young group. hMSC transplantation may improve cardiac function, but MSC source may affect therapeutic efficacy. Similar data were obtained from TUNEL, immunohistochemistry and

\section{KARGER}

(c) 2014 S. Karger AG, Basel

$0008-6312 / 14 / 1282-0209 \$ 39.50 / 0$

E-Mail karger@karger.com

www.karger.com/crd
Western blot. Conclusion: Transplantation of hMSCs improves heart function, but proliferative ability and myocardial protection decrease with older MSCs, likely due to differences between VEGF and $\mathrm{BCl}-2$ expression and reduced antiapoptosis.

(c) 2014 S. Karger AG, Basel

\section{Instruction}

Coronary heart disease (CHD) is a leading cause of cardiovascular mortality worldwide, with more than 4.5 million deaths in the developing world [1]. For instance, approximately $13-22 \%$ of cardiovascular patients die annually because of CHD in China, making this the second leading cause of cardiovascular death in this country [2]. In the developed world, the mortality of CHD is still unacceptably high. In the USA, nearly 1 million Americans suffer from CHD, almost 25\% of whom will die from this condition [3]. Many therapeutic methods have been used to treat $\mathrm{CHD}$, including drug therapy, interventional therapy and coronary artery bypass grafting. Also, mesenchymal stem cell (MSCs) transplantation is reported to be an effective

Y.L., T.L. and J.H. have contributed equally to this article. 
method for protecting the damaged myocardium and improving cardiac function [4].

MSCs expressing CD105, CD90 and CD29 (and rarely CD45, CD34 and HLA-DR) can be isolated from bone marrow, adipose tissue and umbilical cord blood [5]. Because MSCs are multipotent, they may differentiate into various cell lineages, such as osteoblasts, adipocytes, chondrocytes, myoblasts and connective tissue, among other tissues [6]. Heart function is improved when MSC transplantation is used to promote angiogenesis, myogenesis, inhibition of left ventricular (LV) remodeling, and certain paracrine effects $[7,8]$. Of these mechanisms for improving cardiac function, paracrine effects hold great significance [8]. Paracrinemediated secretion of various cytokines such as vascular endothelial growth factor (VEGF) and hepatocyte growth factor [9] from MSCs may contribute to cardiac repair by minimizing ischemic reperfusion injury via cytoprotection, neovascularization and inhibition of apoptosis $[10,11]$. Although both animal and clinical studies have confirmed that MSC transplantation may benefit CHD patients, the efficacy of this therapeutic intervention is uncertain. Most CHD patients from whom MSCs can be obtained are older patients who have fewer MSCs and less MSC differentiation/regeneration and mobilization capacities $[12,13]$. For example, the biological characteristics of MSCs were previously described in a rat model and in patients with CHD. In this report, MSCs had impaired therapeutic transplant efficacy for myocardial infarction (MI) when obtained from old mice, and this was related to pigment epithelium-derived factor (PEDF). Previous studies have focused on the biological characteristics of MSCs in a rat model [14] and in patients with CHD [15]. Thus, aging may influence the efficacy of MSC transplantation $[6,16]$, but at present the importance of MSC donor age on therapeutic efficacy is uncertain [17]. Therefore, in this work, we focused on the differences in biological characteristics of MSCs obtained from young and old CHD patients to determine whether older MSCs can be optimized sufficiently to provide post-MI therapy in older patients.

\section{Methods}

Isolation and Culture of Human MSCs

Bone marrow collection for research purposes was approved by the Ethics Committee of the Shenyang Northern Hospital, Shenyang City, China. MSCs were isolated and cultured as previously reported [18]. Briefly, at the time of coronary artery bypass
Table 1. Inclusion and exclusion criteria

\begin{tabular}{ll}
\hline Inclusion criterion & Male \\
& Age $>60$ years or $<45$ years. \\
& Acute MI. \\
& Multiple vessels involved. \\
\hline Exclusion criterion & $\begin{array}{l}\text { Infectious, systemic immunologic diseases, } \\
\text { malignancy, hepatic and nephritic } \\
\text { dysfunction, diabetes mellitus. }\end{array}$ \\
\hline
\end{tabular}

Table 2. Patient demographics

\begin{tabular}{lccc}
\hline Categories & Old $(\mathrm{n}=10)$ & Young $(\mathrm{n}=10)$ & $\mathrm{p}$ value \\
\hline Age, years & $69.90(5.72)$ & $42.12(1.81)$ & 0.000 \\
BMI, kg/m $\mathrm{m}^{2}$ & $25.32(2.76)$ & $27.44(1.92)$ & 0.084 \\
LVEF, \% & $43.93(5.57)$ & $43.88(4.16)$ & 0.982 \\
Smoker & 6 & 4 & 0.656 \\
Hypertension & 5 & 3 & 0.650 \\
Hyperlipidemia & 2 & 3 & 1.000 \\
Target vessel & & & \\
$\quad$ LM & 4 & 3 & 1.000 \\
$\quad$ LAD & 10 & 10 & 1.000 \\
LCX & 5 & 3 & 0.650 \\
RCA & 4 & 7 & 0.370 \\
OM & 3 & 2 & 1.000 \\
$\quad$ Diagonal & 3 & 1 & 0.582 \\
\hline
\end{tabular}

Values are presented as $\mathrm{n}$, or mean with SD in parentheses. $\mathrm{LVEF}=$ Left ventricular ejection fraction; $\mathrm{LM}=$ left main coronary artery; LAD = left anterior descending coronary artery; RCA = right coronary artery; $\mathrm{OM}=$ obtuse marginal.

graft surgery (CABG), bone marrow was aspirated from the sternum and then mixed immediately with heparin. Patients were divided into young ( $<45$ years old) and old ( $>60$ years old) groups $(\mathrm{n}=10)$. Table 1 depicts the inclusion and exclusion criteria. Patient demographic and clinical data are summarized in table 2 . All patients provided informed consent and the study was conducted according to the ethical guidelines of the Declaration of Helsinki (1975).

The marrow samples were washed twice with PBS after centrifugation at $900 \mathrm{~g}$ for $10 \mathrm{~min}$ to discard the fat layer. The residual cells were added into an equal volume of $1.073 \mathrm{~g} / \mathrm{ml}$ Percoll solution in a $50-\mathrm{ml}$ conical tube and centrifuged at $1,100 \mathrm{~g} / \mathrm{min}$ for $30 \mathrm{~min}$. Mononuclear cells were collected from the upper layer and interface, diluted with two volumes of PBS, and collected by centrifugation at $1,100 \mathrm{~g} / \mathrm{min}$. The cells were seeded in low-glucose Dulbecco's Modified Eagle Medium (Gibco, Grand Island, N.Y., USA) supplemented with $10 \%$ fetal bovine serum (Gibco, Mulgrave, Victoria, Australia), $100 \mathrm{U} / \mathrm{ml}$ penicillin and $100 \mathrm{mg} / \mathrm{ml}$ streptomycin. The nucleated cells were plated into $100-\mathrm{mm}$ plastic culture dishes (Beckton Dickinson, San Jose, Calif., USA) and in- 
cubated at $37^{\circ} \mathrm{C}$ in $5 \% \mathrm{CO}_{2}$ and $95 \%$ humidity. The culture medium was replaced by new medium every $2-3$ days. Adherent cells were cultured until they reached $80 \%$ confluence. The cells were harvested by $0.25 \%$ trypsin and passaged. Passage 3 cells were used for future experiments.

Growth curves of human MSCs (hMSCs) from patients were depicted using the 3-(4, 5-dimethylthiazol-2-yl)-2, 5-diphenyltetrazlium bromide (MTT) assay. Briefly, hMSCs were isolated from both patient groups and cultured in 96-well plastic culture dishes at a density of $2.5 \times 10^{3}$ cells/well. After $1,2,3,4,5,6,7$ and 8 days of culture, MTT (Sigma, St. Louis, Mo., USA) dissolved in PBS was added to each well at a final concentration of $5 \mathrm{mg} / \mathrm{ml}$, and the samples were incubated at $37^{\circ} \mathrm{C}$ for $4 \mathrm{~h}$. Water-insoluble dark blue formazan crystals formed during MTT cleavage in actively metabolizing cells and these crystals were dissolved in dimethyl sulfoxide (DMSO; Gibco/Invitrogen, Grand Island, N.Y., USA). Optical density was measured $(\lambda=490 \mathrm{~nm})$ using a Bio-Rad 680 microplate reader (Bio-Rad, Hercules, Calif., USA).

\section{Phenotype Analysis of hMSCs}

hMSCs were trypsinized, incubated and stained with mouse anti-human antibody for $30 \mathrm{~min}$ at room temperature. The cells were then rinsed twice with PBS and resuspended in $500 \mu$ of PBS after centrifugation at $900 \mathrm{~g}$. The cells were analyzed using a flow cytometer (Beckton Dickinson). The antibodies used in this experiment were: CD34-PE, CD45-PE, CD29-PE and CD44-PE (Beckton Dickinson). Approximately $5 \times 10^{5}$ cells per $100 \mu \mathrm{l}$ were labeled with primary mouse antibodies against human CD29, CD34, CD44 and CD45. Cells were incubated at $4{ }^{\circ} \mathrm{C}$ for $30 \mathrm{~min}$ and washed. Mouse IgG1-PE (Beckton Dickinson) was used as an isotype control [19].

\section{Expression of $m R N A$ and Protein in vitro}

RT-PCR analysis was performed as previously described. Briefly, hMSCs were incubated for $48 \mathrm{~h}$ prior to experimentation. Total RNA isolated from hMSCs was used for cDNA synthesis with SuperScript III RNase H-reverse transcriptase (Invitrogen). The cDNA template was amplified with Taq DNA polymerase (Invitrogen). The primers used are shown in table 3.

VEGF concentrations released by hMSCs were measured by ELISA. Briefly, $5 \times 10^{4}$ hMSCs were plated in 24 -well plates in $1 \mathrm{ml}$ of medium. The supernatant was collected after incubation for $48 \mathrm{~h}$. Production of VEGF in supernatant was determined with ELISA using a human VEGF ELISA kit (R\&D Systems, Minneapolis, Minn., USA) according to the manufacturer's instructions.

Bcl-2 protein expression was measured by Western blot. Briefly, hMSCs were treated with cell lysis buffer (Promega, Madison, Wisc., USA). Protein concentration was measured using a BCA protein assay (Pierce, Rockford, Ill., USA). Total proteins $(20 \mu \mathrm{g})$ were separated using $12.5 \%$ sodium SDS-PAGE and transferred to a $0.2-\mathrm{mm}$ nitrocellulose membrane. The membrane was blocked in PBS buffer containing $0.2 \%$ Tween 20 and 5\% non-fat milk for $1 \mathrm{~h}$. The membrane was then incubated overnight at $4^{\circ} \mathrm{C}$ with rabbit $\mathrm{Bcl}-2$ protein polyclonal antibody (1:2,000 dilution; Abcam, Cambridge, Mass., USA). Housekeeping protein $\beta$-actin was used as a loading control. Antibody binding was detected using horseradish peroxidase conjugated secondary antibody and visualized by an ECL kit (Amersham Biosciences, Piscataway, N.J., USA).

Advanced Age Impairs Cardioprotective

Function of MSC Transplantation
Table 3. RT-PCR primers used

\begin{tabular}{ll}
\hline Gene & Primer \\
\hline VEGF(F) & $5^{\prime}$-CTA CCT CCA CCA TGC CAA GT-3' \\
VEGF(R) & $5^{\prime}$-GCA GTA GCT GCG CTG ATA GA-3' \\
Bcl-2(F) & $5^{\prime}$-ATC GCC CTG TGG ATG ACT GAG-3' \\
Bcl-2(R) & $5^{\prime}$-CAG GCC CCA GGA GAA ATC AAA CAG \\
& AGG-3' \\
$\beta$-Actin(F) & $5^{\prime}$-TCT GGC ACC ACA CCT TCT ACA ATG-3' \\
$\beta$-Actin(R) & $5^{\prime}$-AGC ACA GCC TGG ATA GCA ACG-3' \\
\hline
\end{tabular}

\section{Formation and hMSC Transplantation}

To prevent immunorejection, all animals received cyclosporine (10 mg/kg/day; Novartis, Basel, Switzerland) for 4 weeks posttransplantation. Male Sprague-Dawley rats (280-300 g) were divided into three groups (old, young and control groups, $\mathrm{n}=15$ per group). All animals received humane care and all animal protocols complied with the institution's guidelines.

Rats were anesthetized using pentobarbital (50 mg/kg, i.p.), and respiration was assisted with $100 \% \mathrm{O}_{2}$ via a ventilator. Through a left lateral thoracotomy, the proximal portion of the left anterior descending artery was ligated with a 6-0 Prolene suture (Ethicon, Somerville, N.J., USA). MSCs were dissociated and suspended in culture medium at a concentration of $2 \times 10^{6}$ cells in $50 \mu \mathrm{l}$ and were kept on ice until transplantation. Animals in the old $(n=12)$ and young $(n=9)$ groups received a subepicardial injection of hMSCs obtained from old and young patients, respectively. Cells were injected into the infarcted scar and adjacent myocardium. The control group $(n=11)$ received injections of culture medium into the same area. Intramuscular penicillin G benzathine $(100,000 \mathrm{U} / \mathrm{kg})$ was used to prevent infection.

\section{Echocardiography}

Cardiac function was evaluated by echocardiography prior to and at 1 and 4 weeks after MI, MSC or medium injection. Images were recorded using a $12-\mathrm{MHz}$ high-frequency liner phased-array transducer (Philips SONOS 5500, Bothell, Wash., USA). LV end diastolic and systolic dimensions were derived from two-dimensionally targeted M-mode tracings obtained along the parasternal short-axis view of the left ventricle at the papillary muscle level. The ejection fraction (EF) and fractional shortening (FS) were calculated. EF was calculated on the basis of the Teichholz formula, while FS was calculated as follows: $\left(\mathrm{LVD}_{\mathrm{d}}-\mathrm{LVD}_{\mathrm{s}}\right) / \mathrm{LVD} \times 100$, where $\mathrm{LVD}_{\mathrm{d}}$ is $\mathrm{LV}$ diastolic dimension and $\mathrm{LVD}_{\mathrm{s}}$ is $\mathrm{LV}$ systolic dimension. All measurements were performed and averaged over three consecutive cardiac cycles.

\section{TUNEL Staining}

The histochemical detection of apoptotic cells was performed as previously reported [20]. The tissue blocks were fixed in $4 \%$ paraformaldehyde and incubated with proteinase K. Fragments of DNA in the tissue sections were analyzed using a TUNEL detection kit (Promega). For each slide, color images of 10 separate fields were captured randomly and digitized. Cells with clear nuclear labeling were defined as TUNEL-positive cells. The apoptotic index was calculated as the number of TUNEL-positive cells/total number of myocytes. 
Immunohistochemistry

Myocardial tissue was embedded in paraffin and cut into $5-\mu \mathrm{m}$ sections. Detection of Bcl-2 and Bax expression was performed as described previously [21]. Tissue sections were exposed overnight to rabbit Bcl-2 protein polyclonal antibody (1: 2,000 dilution; Abcam) and rabbit Bax protein polyclonal antibody (1:2,000 dilution; Abcam) at $4^{\circ} \mathrm{C}$, washed in PBS and incubated with biotinylated goat anti-rabbit IgG for $60 \mathrm{~min}$ at $37^{\circ} \mathrm{C}$. After two washing steps, sections were exposed to a streptavidinhorseradish-peroxidase complex for $30 \mathrm{~min}$ at $37^{\circ} \mathrm{C}$ and visualized with $3,3^{\prime}$-diaminobenzidine, embedded in glycerol gelatin. Images were captured digitally and analyzed using IPP version 6.0. Cytoplasmic staining was considered positive, and scored as: absent $(-)$; weakly positive $(+)$, moderately positive $(++)$ or strongly positive $(+++)$.

\section{Measurement of Capillary Density}

The number of capillary vessels was counted as described previously [22] using paraffin-embedded sections stained with antifactor VIII antibody (U0034; Dako A/S, Glostrup, Denmark). The number of capillaries in five randomly selected high-power fields in the LV-free wall was averaged and expressed as the number of capillary vessels per high-power field $\left(0.2 \mathrm{~mm}^{2}\right)$.

\section{Western Blot Analysis}

Myocardial tissue samples were homogenized in RIPA buffer, and then total protein was collected. Bcl-2 and VEGF protein expression were measured with Western blot as described above.

\section{Statistical Analysis}

Data were analyzed using SPSS version 12.0 for Windows (SPSS, Chicago, Ill., USA). All variables were presented as means and standard deviations. The t test was used to compare treatments in the in vitro experiments. The results of hMSC transplantation into rat models were tested using one-way analysis of variance. Tukey's method was used for post hoc analysis. $\mathrm{p}<0.05$ was considered statistically significant.

\section{Results}

\section{Growth Characteristics of hMSCs}

hMSCs were tightly attached to the culture dishes after $24 \mathrm{~h}$. They appeared as spindle-shaped cells after 3-4 days of culture of the primary passage, after which they proliferated rapidly. After 11-13 days of primary culture the hMSCs reached nearly $80 \%$ confluences. The hMSCs in passage 3 from the old group had a more flattened appearance and were larger in size than those from the young group (fig. 1a).

\section{Proliferative Abilities of MSCs from Each Group}

Growth curves were characterized by an initial lag phase (during the first 2 days) followed by a log phase (from day 3 to 7 ) during which cells divided at exponential rates. This was followed by a plateau phase after day 8 .
The proliferative potential of hMSCs obtained from old patients was significantly impaired relative to that observed in cells from young patients $(\mathrm{p}<0.05)$. These differences were apparent at each time point after day 3 (fig. 1b).

\section{Phenotype of hMSCs}

hMSCs from both the old and young groups contained a unique phenotypic population which was identified by flow cytometric analysis of expressed surface antigens. All hMSCs were uniformly positive (fig. 1c, d).

\section{Expression of VEGF and Bcl-2 at $m R N A$ and Protein in vitro}

After hMSCs were cultured, VEGF and Bcl-2 gene expression in old and young hMSCs were measured. Compared with young hMSCs, VEGF mRNA expression in old hMSCs decreased, on average, nearly 35\% and Bcl-2 mRNA expression was reduced by more than $60 \%$ (fig. 2a).

To confirm the gene expression results, VEGF and Bcl-2 protein was evaluated in vitro, and ELISA and Western bolt was performed on the supernatant and cell samples at the same time points as mentioned above. Data revealed that VEGF protein expression was significantly lower in the old cells compared to the young group, and expression of Bcl-2 protein was similarly reduced in older cells (fig. 2b, c).

\section{Evaluation of Myocardial Function}

Transplantation of hMSCs into the infarcted border zone of rats with experimentally induced MI improved EF significantly, but FS improved insignificantly. There were no remarkable differences in EF and FS among the three groups pre-infarction or at 1 week post-infarction.

In the old and young groups, EF increased significantly relative to the control group after MSC transplantation. However, EF was significantly lower in the old group compared to the young group. However, FS increased significantly in the young group compared with the control and old groups, and there were no significant differences in FS between the old and control groups (fig. 2d, e).

\section{Myocardial Apoptosis after hMSC Transplantation}

The degree of apoptosis 4 weeks after hMSC transplantation was significantly lower in the old and young groups compared to the control group. However, myocardial apoptosis was significantly higher in the old cell group compared to the young group (fig. 3a). 


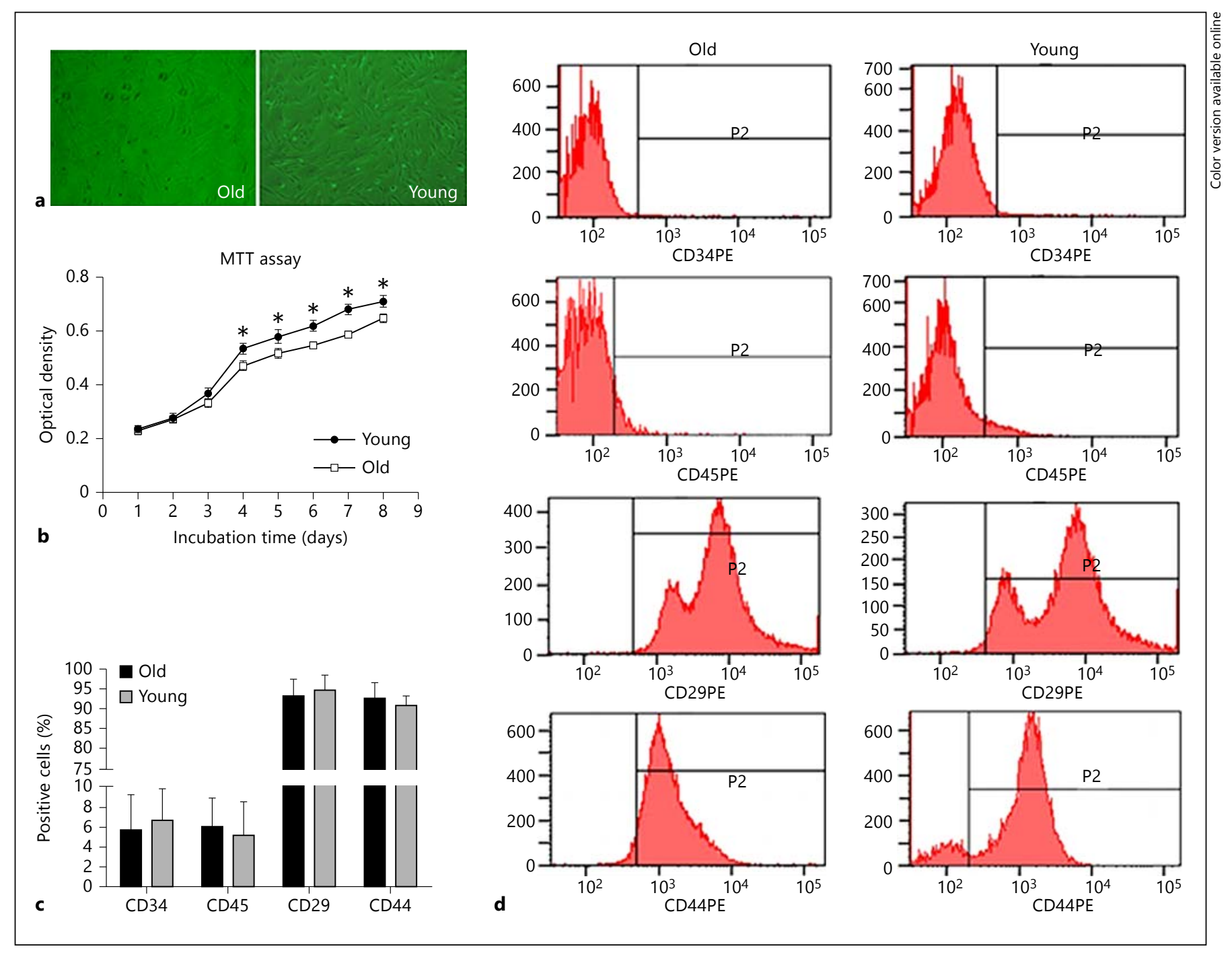

Fig. 1. Characteristics of cultured hMSCs. a In passage 3, the hMSCs from the old group were flatter in appearance and larger than those in the young group. b An MTT assay indicated that the proliferative potential of hMSCs from the old group decreased significantly compared with the young group at each time point at

\section{Immunohistochemistry in Infarcted Myocardium}

Bcl-2 was upregulated and Bax was downregulated by immunohistochemistry in both the old and young groups compared to the control group. Furthermore, compared with the young group, Bcl-2 (fig. 3b) was downregulated and Bax (fig. 3c) was upregulated in the old group.

\section{Capillary Densities}

Blood vessel density was detected with factor VIII (fig. 4a-d). The capillary density stained with a brown color in the LV free wall was significantly higher in the both the log and plateau phase of cell growth after the first 3 days. c Quantification revealed no differences in the percentages of old and young hMSCs. d The phenotype of hMSCs from the old and young groups was negative for CD34 and CD45, and positive for CD29 and CD44. ${ }^{*} \mathrm{p}<0.05$ vs. young group. old and young groups compared to the control group. Furthermore, young cell groups had significantly greater capillary density than the old group.

\section{Protein Expression in Infarcted Myocardium}

Protein expressions of VEGF and Bcl-2 after hMSC transplantation in the old and young groups were both significantly higher than in the control group, as evidenced by Western blot. However, VEGF and Bcl-2 expression in the old group was significantly lower than in the young group (fig. $4 \mathrm{e}, \mathrm{f}$ ). 


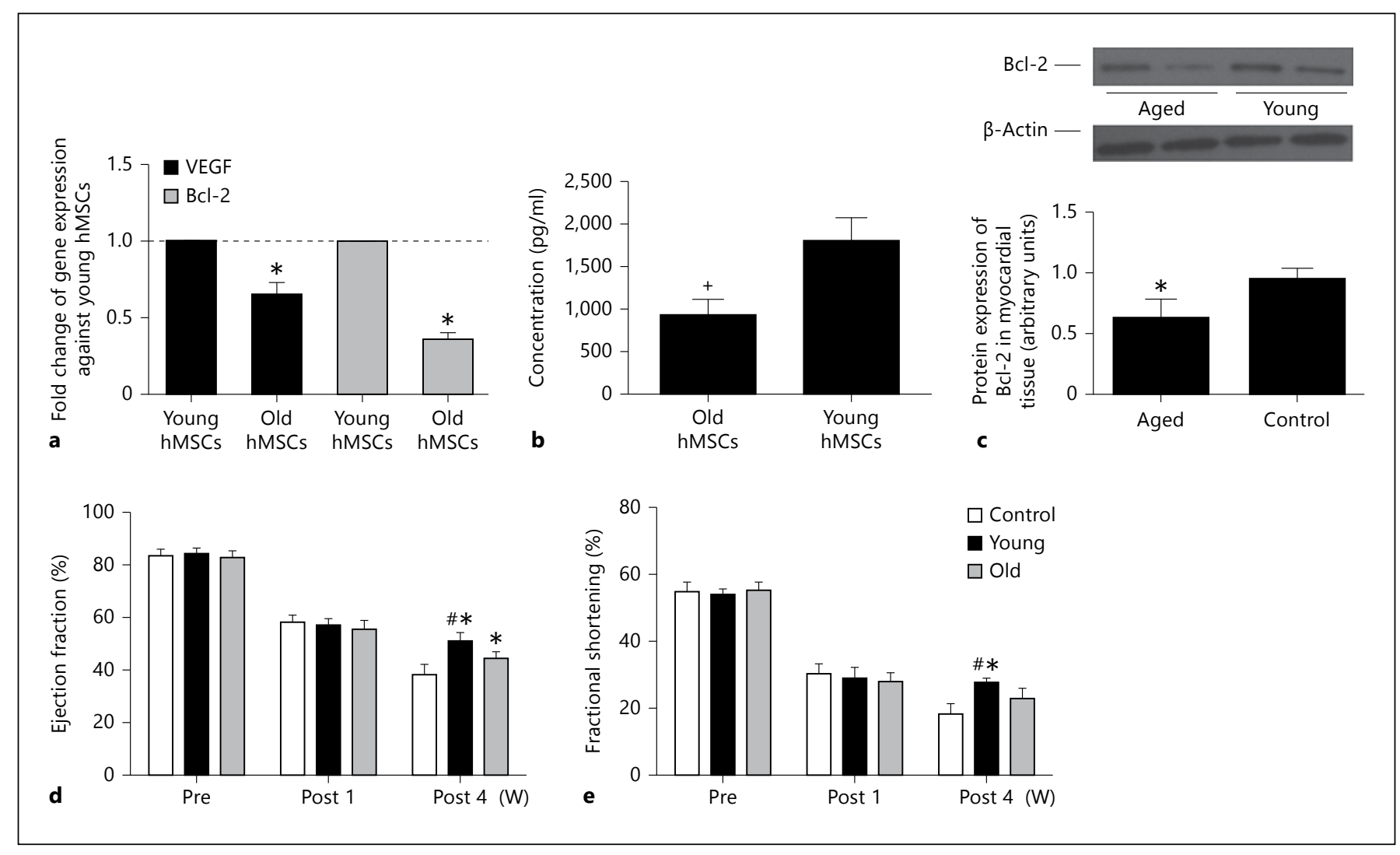

Fig. 2. Cytokine expression in hMSCs and evaluation of myocardial function after hMSC transplantation. a VEGF and Bcl-2 expression estimated by RT-PCR indicates downregulation in the old group compared with the young group. b Protein expression of VEGF validated by ELISA indicated downregulation in the old group compared with the young group. $\mathbf{c}$ Western blot validation of Bcl-2 protein revealed downregulation in the old group compared with the young group. EF (d) and FS (e) in the three groups were not significantly different before and 1 week after operation. EF in the old and young groups was increased significantly after MSC transplantation, while FS increased only in the young group. Furthermore, EF and FS decreased significantly in the old group compared with the young group 4 weeks post-operation. ${ }^{+} \mathrm{p}<0.05$ compared with the young group; ${ }^{*} \mathrm{p}<0.05$ compared with the control group; ${ }^{\#} \mathrm{p}<0.05$ compared with the old group.

\section{Discussion}

Many factors may impair the effect of MSC therapy, such as diabetes [23], myocarditis [20] and antineoplastic drug treatment [21]. Thus, advanced age is only one risk factor [24]. Therefore, we used rigid inclusion and exclusion criteria to rule out the influence of other factors except advanced age.

In the present study, we used hMSCs from the third passage of culture for in vitro and in vivo experiments. hMSCs from passages 1 to 5 had significantly greater proliferative potential than those from later passages [15]. Initially, we discovered that proliferation of hMSCs derived from old patients were significantly different than those derived from young patients, offering prelim- inary evidence that senescence reduces the proliferation of hMSCs in vitro. Our data were consistent with previous reports that an important degenerative factor in senescence is the accumulation of cell damage [25]. However, the differentiation potential of MSCs did not change with age [26]. Experiments in vitro also indicated that VEGF and Bcl-2 mRNA level and protein expression decreased in the old group compared with the young group. Both of these cytokines may play an important role in hMSC proliferation [27, 28]. Also, transplantation of hMSCs from old patients and young patients into a rat MI model improved cardiac contractility and attenuated apoptosis of cardiomyocytes. However, these effects diminished in hMSCs derived from old patients. Furthermore, the capillary density in the LV free wall was mea- 

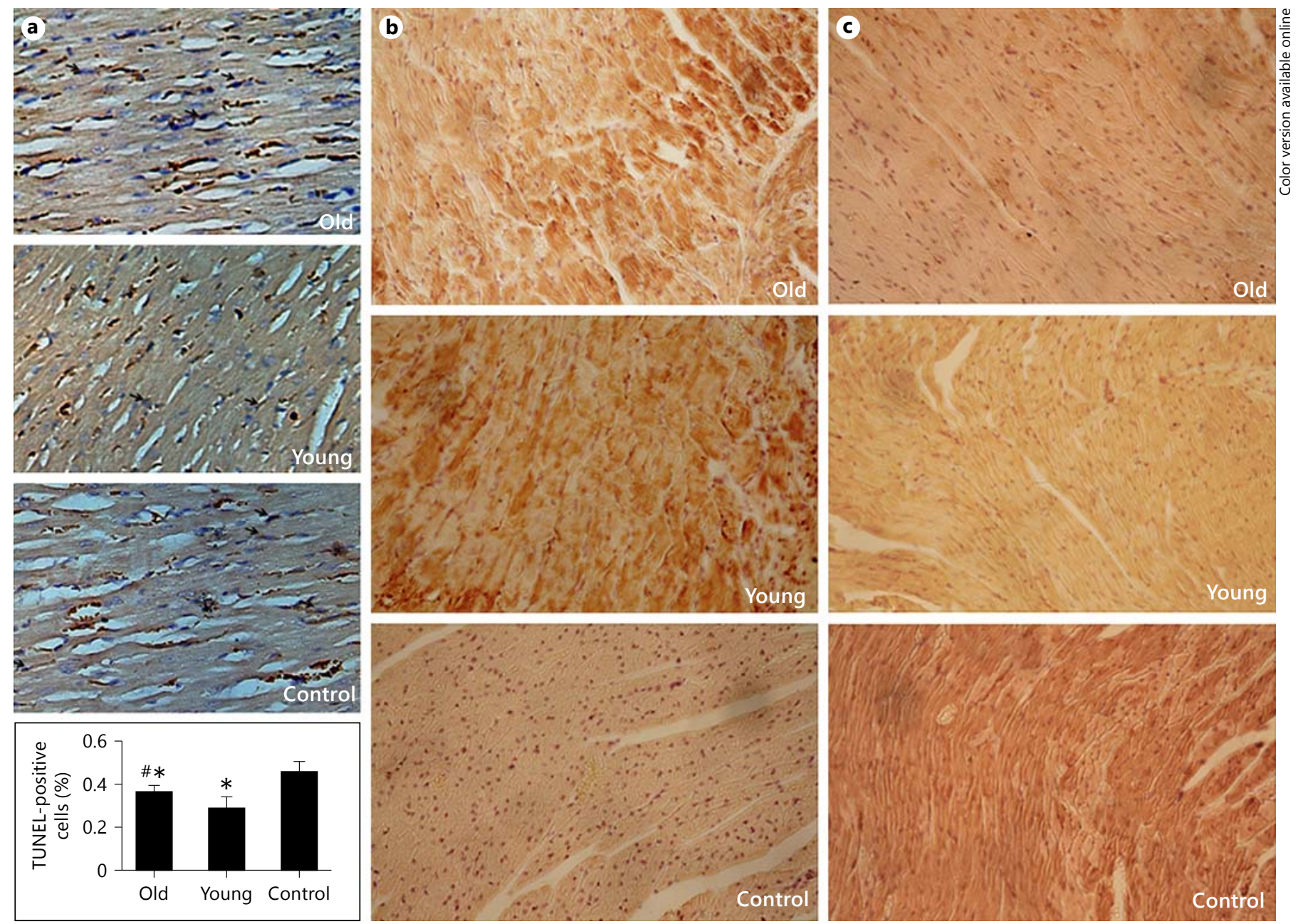

Fig. 3. Myocardial apoptosis at 4 weeks after hMSC transplantation. a Myocardial apoptosis was detected by TUNEL staining. TUNEL-positive cells (arrow) decreased significantly in the old and young groups compared with the control group. Furthermore, TUNEL-positive cells increased significantly in the old group in contrast to the young group. Immunohistochemical detection of

sured and the young group had the greatest capillary density, and the capillary density in the old group was also higher than in the control group. These findings may be explained by decreased expression of VEGF and Bcl-2, which may weaken the effect of angiogenesis and anti-apoptosis.

In our study, we measured VEGF and Bcl-2 expression in hMSCs. VEGF is a cell-signaling protein produced that stimulates vasculogenesis and angiogenesis [29], and this is mediated partially through the antiapoptotic effects of the PI3K/AKT-dependent pathway [30]. Bcl-2 (of the Bcl-2 family) and VEGF are overex-

Advanced Age Impairs Cardioprotective

Function of MSC Transplantation apoptosis-related protein including Bcl-2 (b) and Bax (c) expression in infarcted myocardium from the control $(+)$, old $(++)$ and young $(+++)$ groups, and control $(+++)$, old $(++)$ and young $(+)$ groups, respectively. ${ }^{*} \mathrm{p}<0.05$ vs. control group; ${ }^{\#} \mathrm{p}<0.05$ vs. CAD group.

pressed in B cell lymphoma [31]. Bcl-2 family proteins are critical regulators of pathways involved in anti-apoptosis and cell death inhibition [32]. In the present study, mRNA and protein expression of VEGF and Bcl-2 were significantly lower in the old group compared to the young group, suggesting that VEGF and Bcl-2 expression in patients with CAD might be impaired by senescence, which may decrease the anti-apoptotic function of hMSCs.

Previous reports have emerged that MSCs are immune-tolerant and express low levels of major histocompatibility complex and co-stimulant molecules [33]. This 

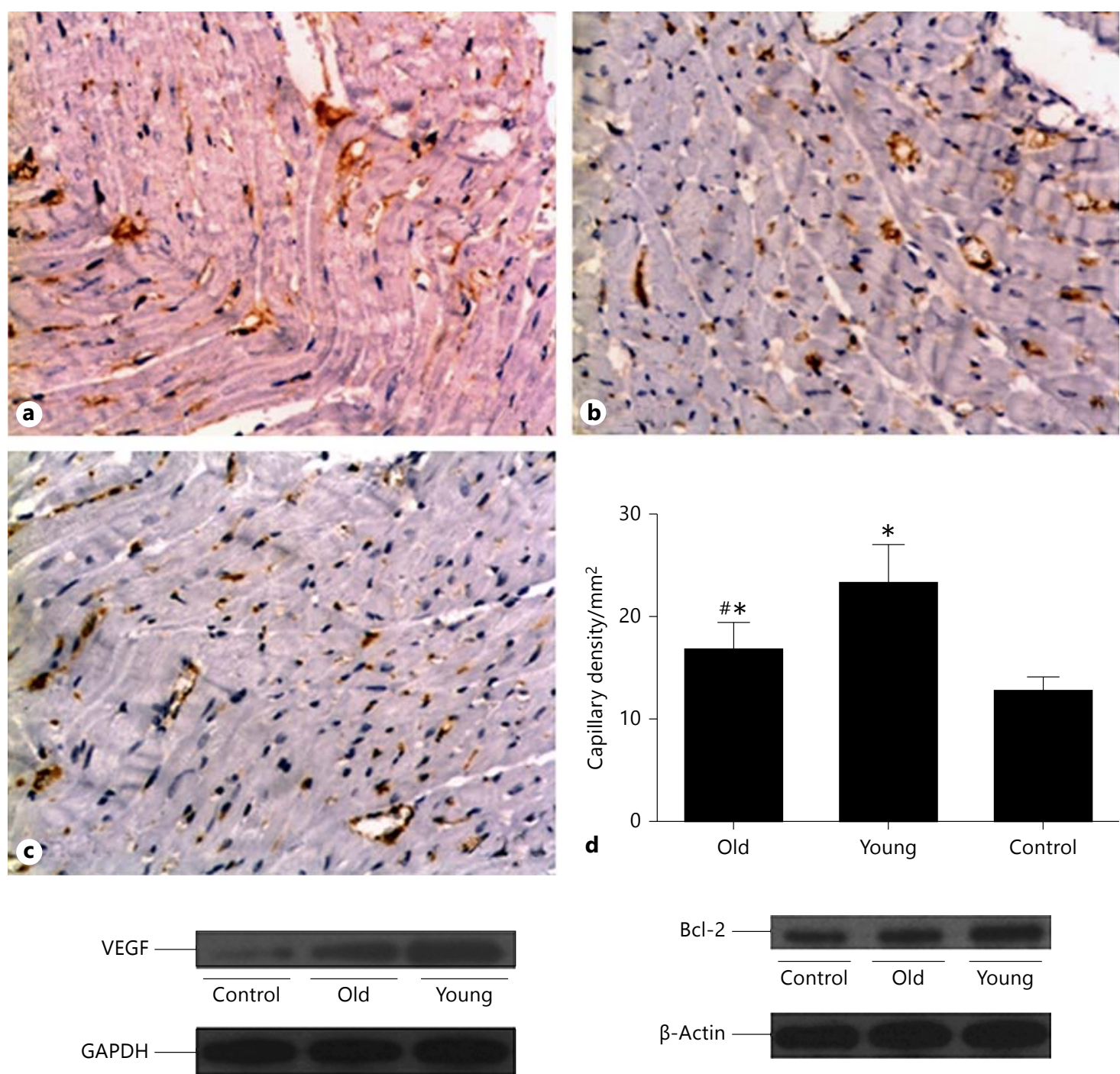

$\beta$-Actin -
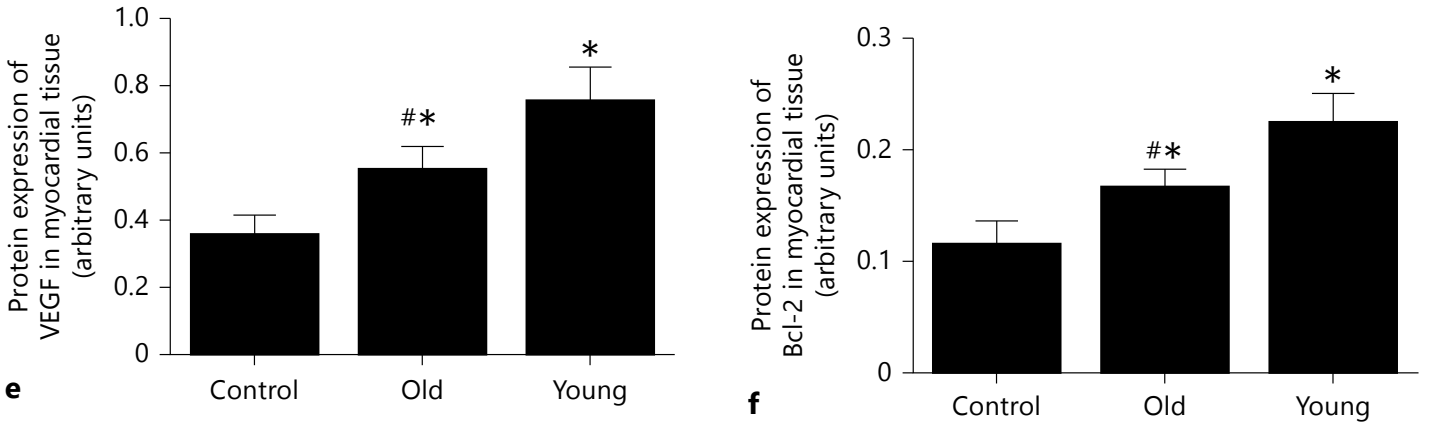

Fig. 4. Angiogenesis and protein expression in infarcted myocardium. a Representative sections from old (a), young (b) and control (c) hearts are stained with anti-factor VIII antibody (original magnification $\times 200$ ) and capillary densities are shown. Capillary density in the old group decreased compared with the young group, but increased compared with the control group (d). West-

ern blot revealed that hMSC transplantation from the old and young significantly elevated VEGF (e) and Bcl-2 (f) expression in the myocardium compared with the control group. Moreover, both VEGF and Bcl-2 protein decreased significantly in the old group compared with the young group. ${ }^{*} \mathrm{p}<0.05$ vs. control group; ${ }^{\#} \mathrm{p}<0.05 \mathrm{vs}$. young group. 
means that MSCs are generally safe and effective when used for allotransplantation [12]. However, we used heterotransplantation which made post-transplant rejection a concern [34]. Therefore, cyclosporine was used to suppress the immune response in our study. However, the cardioprotective function of reduced infarct size from cyclosporine is controversial, especially in swine $[35,36]$. Still, all treated animals were administered cyclosporine at the same time and dose in order to prevent any potential influence from it.

In vivo experiments, we found that hMSC transplantation improved myocardial function but that the improvement was significantly more marked with cells derived from young patients than with those derived from old patients. The myocardial protective function of hMSC transplantation may be diminished by aging and this is a finding that is in accordance with previous studies [37]. In our study, myocardial tissue from the infarcted zone and border was studied using TUNEL, immunohistochemistry and Western blot. We found that apoptosis of myocardial cells increased dramatically, while the capillary density decreased significantly in the old group compared with the young group. We also showed that expression of VEGF and Bcl-2 decreased markedly in the old group compared with the young group. VEGF expression in vitro at the mRNA and protein level was reduced in the old group compared with the young group. However, in vivo, protein expression of VEGF after hMSC transplantation decreased dramatically in the old group compared with the young group. This might be due to elevated VEGF secretion in response to hypoxia [38]. Thus, dramatically different levels of VEGF were observed in cells cultured under normoxic conditions versus infarcted myocardium under hypoxic conditions. In contrast, Bcl-2 expression was similar under both normoxic and hypoxic conditions. Thus, inhibition of Bcl-2 expression may result in increased apoptosis of donor cells, whereas decreased secretion of VEGF may weaken the angiogenesis function of cell transplantation and induce apoptosis of myocardial cells through the PI3K/ AKt-dependent pathway. A combination these events may impair the cardioprotective function of hMSCs used for transplantation. In addition, previous work suggests that genetic modification with the anti-apoptotic $\mathrm{Bcl}-2$ gene increased VEGF expression in response to hypoxia [39], which means that high Bcl-2 expression partially contributes to increased VEGF secretion in hypoxia. Our data agree with this study.

To enhance the cardioprotective effect of old MSC transplantation, some techniques may be useful. For ex-

Advanced Age Impairs Cardioprotective

Function of MSC Transplantation ample, modification of hMSCs from old patients using VEGF and/or Bcl-2 gene expression may improve VEGF and $\mathrm{Bcl}-2$ protein expression and enhance the ability of hMSCs to protect the ischemic myocardium. Previously, we confirmed that PEDF can impair the therapeutic efficacy of MSCs in the attenuation of MI injury [37], and this impairment can be suppressed by VEGF [40]. Thus, optimization of VEGF and PEDF concentrations may be a genetically modifiable target for increasing the therapeutic function of MSCs from old patients. Also, because of poor stem cell transplant viability due to tissue ischemia and local inflammation, modulation of the myocardial microenvironment may offer an alternative method. A recent study suggests that rosuvastatin enhanced survival and viability of MSCs after transplantation, protecting against ischemia-reperfusion cardiac injury, suppressing inflammation and reducing apoptosis of cardiomyocytes [41]. Thus, combined drug therapy with statins may be beneficial for MSC transplantation.

\section{Limitations}

Previous studies indicate that aging impairs the quantity, quality and mobilization capacity of MSCs [6]. Thus, hMSCs were obtained from patients older than 60 years of age (the old group) and younger than 40 years of age (the young group) according to young and old WHO criteria. However, retrospective studies indicated that only 1 or 2 patients younger than 40 years of age received CABG in our heart center (of 500-600 total $\mathrm{CABG}$ cases per year). Future studies will require selection of even more patients younger than 45 years of age to capture more 'young' patients. Thus, the relatively small sample size used here may influence the data. Our findings must to be substantiated in larger populations of patients.

\section{Conclusions}

The present study indicates that hMSCs from young and old patients have proliferative properties, and that transplantation of hMSCs from all patients improved heart function in rats with MI. The ability to proliferate and ameliorate myocardial function decreased significantly in MSCs obtained from old patients compared with those obtained from young patients. These differences may be attributed to differences in VEGF and Bcl-2 protein expression, which determine the extent of antiapoptosis. 


\section{Acknowledgements}

This study was funded in part by the National Science Foundation of China (81071267). We thank LetPub for its linguistic assistance during the preparation of this manuscript.

\section{Conflict of Interest}

The authors declare that they have no competing interests.

\section{References}

1 Okrainec K, Banerjee D, Eisenberg M: Coro- 12 Hare JM, Traverse JH, Henry TD, Dib N, nary artery disease in the devleoping world. Am Heart J 2004;1:7-15.

$>2$ Zhang XH, Lu ZL, Liu L: Coronary heart disease in China. Heart 2008;94:1126-1131.

3 Boilson BA, Gulati R: Stem cell therapy for the heart: a perspective. Transl Res 2010;155:3-5.

$\checkmark 4$ Quevedo HC, Hatzistergos KE, Oskouei BN, Feigenbaum GS, Rodriguez JE, Valdes D, Pattany PM, Zambrano JP, Hu Q, McNiece I, Heldman AW, Hare JM: Allogeneic mesenchymal stem cells restore cardiac function in chronic ischemic cardiomyopathy via trilineage differentiating capacity. Proc Natl Acad Sci USA 2009;106:14022-14027.

5 Dominici M, Le Blanc K, Mueller I, SlaperCortenbach I, Marini F, Krause D, Deans R, Keating A, Prockop D, Horwitz E: Minimal criteria for defining multipotent mesenchymal stromal cells. The international society for cellular therapy position statement. Cytotherapy 2006;8:315-317.

6 Sethe S, Scutt A, Stolzing A: Aging of mesenchymal stem cells. Ageing Res Rev 2006;5:91116.

7 Krause U, Harter C, Seckinger A, Wolf D, Reinhard A, Bea F, Dengler T, Hardt S, Ho A, Katus HA, Kuecherer H, Hansen A: Intravenous delivery of autologous mesenchymal stem cells limits infarct size and improves left ventricular function in the infarcted porcine heart. Stem Cells Dev 2007;16:31-37.

8 Caplan AI, Dennis JE: Mesenchymal stem cells as trophic mediators. J Cell Biochem 2006;98:1076-1084.

9 Wang M, Crisostomo PR, Herring C, Meldrum KK, Meldrum DR: Human progenitor cells from bone marrow or adipose tissue produce VEGF, HGF, and IGF-I in response to TNF by a p38 MAPK-dependent mechanism. Am J Physiol Regul Integr Comp Physiol 2006;291:R880-R884.

$\checkmark 10$ Kupatt C, Horstkotte J, Vlastos GA, Pfosser A, Lebherz C, Semisch M, Thalgott M, Buttner K, Browarzyk C, Mages J, Hoffmann R, Deten A, Lamparter M, Muller F, Beck H, Buning H, Boekstegers P, Hatzopoulos AK: Embryonic endothelial progenitor cells expressing a broad range of proangiogenic and remodeling factors enhance vascularization and tissue recovery in acute and chronic ischemia. FASEB J 2005;19:1576-1578.

11 Gnecchi M, Zhang Z, Ni A, Dzau VJ: Paracrine mechanisms in adult stem cell signaling and therapy. Circ Res 2008;103:1204-1219.
Strumpf RK, Schulman SP, Gerstenblith G, DeMaria AN, Denktas AE, Gammon RS, Hermiller JJ, Reisman MA, Schaer GL, Sherman W: A randomized, double-blind, placebo-controlled, dose-escalation study of intravenous adult human mesenchymal stem cells (prochymal) after acute myocardial infarction. J Am Coll Cardiol 2009;54:22772286.

13 Cui X, Wang H, Guo H, Wang C, Ao H, Liu $\mathrm{X}$, Tan YZ: Transplantation of mesenchymal stem cells preconditioned with diazoxide, a mitochondrial ATP-sensitive potassium channel opener, promotes repair of myocardial infarction in rats. Tohoku J Exp Med 2010;220:139-147.

14 Jin P, Zhang X, Wu Y, Li L, Yin Q, Zheng L, Zhang H, Sun C: Streptozotocin-induced diabetic rat-derived bone marrow mesenchymal stem cells have impaired abilities in proliferation, paracrine, antiapoptosis, and myogenic differentiation. Transplant Proc 2010;42:27452752.

$>15$ Hou M, Yang KM, Zhang H, Zhu WQ, Duan FJ, Wang H, Song YH, Wei YJ, Hu SS: Transplantation of mesenchymal stem cells from human bone marrow improves damaged heart function in rats. Int J Cardiol 2007;115: 220-228.

16 Fan M, Chen W, Liu W, Du GQ, Jiang SL, Tian WC, Sun L, Li RK, Tian H: The effect of age on the efficacy of human mesenchymal stem cell transplantation after a myocardial infarction. Rejuvenation Res 2010;13:429-438.

17 Dimmeler S, Leri A: Aging and disease as modifiers of efficacy of cell therapy. Circ Res 2008;102:1319-1330.

18 Liu Y, Li Z, Liu T, Xue X, Jiang H, Huang J, Wang H: Impaired cardioprotective function of transplantation of mesenchymal stem cells from patients with diabetes mellitus to rats with experimentally induced myocardial infarction. Cardiovasc Diabetol 2013;12:40.

19 Campagnoli C, Roberts IA, Kumar S, Bennett PR, Bellantuono I, Fisk NM: Identification of mesenchymal stem/progenitor cells in human first-trimester fetal blood, liver, and bone marrow. Blood 2001;98:2396-2402.

20 Brunner S, Theiss HD, Leiss M, Grabmaier U, Grabmeier J, Huber B, Vallaster M, Clevert DA, Sauter M, Kandolf R, Rimmbach C, David R, Klingel K, Franz WM: Enhanced stem cell migration mediated by VCAM-1/VLA-4 interaction improves cardiac function in vi- rus-induced dilated cardiomyopathy. Basic Res Cardiol 2013;108:388.

21 Piegari E, De Angelis A, Cappetta D, Russo R, Esposito G, Costantino S, Graiani G, Frati C, Prezioso L, Berrino L, Urbanek K, Quaini F, Rossi F: Doxorubicin induces senescence and impairs function of human cardiac progenitor cells. Basic Res Cardiol 2013;108:334.

22 Sakaguchi G, Tambara K, Sakakibara Y, Ozeki $M$, Yamamoto $M$, Premaratne $G$, Lin $X$, Hasegawa K, Tabata Y, Nishimura K, Komeda $\mathrm{M}$ : Control-released hepatocyte growth factor prevents the progression of heart failure in stroke-prone spontaneously hypertensive rats. Ann Thorac Surg 2005;79:1627-1634.

23 Fadini GP, Albiero M, Seeger F, Poncina N, Menegazzo L, Angelini A, Castellani C, Thiene G, Agostini C, Cappellari R, Boscaro E, Zeiher A, Dimmeler S, Avogaro A: Stem cell compartmentalization in diabetes and high cardiovascular risk reveals the role of DPP-4 in diabetic stem cell mobilopathy. Basic Res Cardiol 2013;108:313.

24 Boengler K, Schulz R, Heusch G: Loss of cardioprotection with ageing. Cardiovasc Res 2009;83:247-261

25 Gao J, Dennis JE, Muzic RF, Lundberg M, Caplan AI: The dynamic in vivo distribution of bone marrow-derived mesenchymal stem cells after infusion. Cells Tissues Organs 2001;169: 12-20.

26 Tokalov SV, Gruner S, Schindler S, Wolf G, Baumann M, Abolmaali N: Age-related changes in the frequency of mesenchymal stem cells in the bone marrow of rats. Stem Cells Dev 2007;16:439-446.

27 Bonnefoy-Berard N, Aouacheria A, Verschelde C, Quemeneur L, Marcais A, Marvel J: Control of proliferation by Bcl-2 family members. Biochim Biophys Acta 2004;1644:159-168.

28 Deissler H, Deissler H, Lang S, Lang GE: VEGFinduced effects on proliferation, migration and tight junctions are restored by ranibizumab (Lucentis) in microvascular retinal endothelial cells. Br J Ophthalmol 2008;92:839-843.

29 Ferrara N: Role of vascular endothelial growth factor in physiologic and pathologic angiogenesis: therapeutic implications. Semin Oncol 2002;29:10-14.

$30 \mathrm{Xu}$ XH, Xu J, Xue L, Cao HL, Liu X, Chen YJ: VEGF attenuates development from cardiac hypertrophy to heart failure after aortic stenosis through mitochondrial mediated apoptosis and cardiomyocyte proliferation. J Cardiothorac Surg 2011;6:54. 
31 Gross A, McDonnell JM, Korsmeyer SJ: Bcl-2 family members and the mitochondria in apoptosis. Genes Dev 1999;13:1899-1911.

32 Willis S, Day CL, Hinds MG, Huang DC: The Bcl-2-regulated apoptotic pathway. J Cell Sci 2003;116:4053-4056.

33 Atoui R, Shum-Tim D, Chiu RC: Myocardial regenerative therapy: immunologic basis for the potential 'universal donor cells'. Ann Thorac Surg 2008;86:327-334.

-34 Nauta AJ, Fibbe WE: Immunomodulatory properties of mesenchymal stromal cells. Blood 2007;110:3499-3506.

35 Lim WY, Messow CM, Berry C: Cyclosporin variably and inconsistently reduces infarct size in experimental models of reperfused myocardial infarction: a systematic review and meta-analysis. Br J Pharmacol 2012;165: 2034-2043.
36 Skyschally A, Schulz R, Heusch G: Cyclosporine $A$ at reperfusion reduces infarct size in pigs. Cardiovasc Drugs Ther 2010;24:85-87.

37 Liang $\mathrm{H}$, Hou H, Yi W, Yang G, Gu C, Lau WB, Gao E, Ma X, Lu Z, Wei X, Pei J, Yi D: Increased expression of pigment epitheliumderived factor in aged mesenchymal stem cells impairs their therapeutic efficacy for attenuating myocardial infarction injury. Eur Heart J 2013;34:1681-1690.

38 Nakamura M, Yamabe H, Osawa H, Nakamura N, Shimada M, Kumasaka R, Murakami R, Fujita T, Osanai T, Okumura K: Hypoxic conditions stimulate the production of angiogenin and vascular endothelial growth factor by human renal proximal tubular epithelial cells in culture. Nephrol Dial Transplant 2006;21: 1489-1495.
39 Li W, Ma N, Ong LL, Nesselmann C, Klopsch C, Ladilov Y, Furlani D, Piechaczek C, Moebius JM, Lutzow K, Lendlein A, Stamm C, Li RK, Steinhoff G: Bcl-2 engineered MSCs inhibited apoptosis and improved heart function. Stem Cells 2007;25:2118-2127.

40 Fan W, Crawford R, Xiao Y: The ratio of VEGF/PEDF expression in bone marrow mesenchymal stem cells regulates neovascularization. Differentiation 2011;81:181191.

41 Zhang Z, Li S, Cui M, Gao X, Sun D, Qin X, Narsinh K, Li C, Jia H, Li C, Han Y, Wang H, Cao F: Rosuvastatin enhances the therapeutic efficacy of adipose-derived mesenchymal stem cells for myocardial infarction via PI3K/ Akt and MEK/ERK pathways. Basic Res Cardiol 2013;108:333. 